\title{
Thrombosis and thromboprophylaxis in COVID-19 patients during hospitalization and early post-discharge period
}

\author{
Hosseini Mehr Seyed Pouriya1', Smorzhevskyi Valentyn², Dzekunova Yuliia ${ }^{3}$, \\ Dmytrenko Igor ${ }^{4}$. \\ ${ }^{1}$ Clinical Resident, Department of Surgery and Organ Transplantation, Shalimov National Institute of Surgery and \\ Transplantology, ${ }^{2}$ Professor, Department of Cardiothoracic Surgery, Shalimov National Institute of Surgery and \\ Transplantology, ${ }^{3}$ Clinical Resident, Department of Otorhinolaryngology, A.I. Kolomiychenko National Institute of \\ Otorhinolaryngology, ${ }^{4}$ Consultant Surgeon, Department of Plastic and Reconstructive Surgery, Shalimov National \\ Institute of Surgery and Transplantology
}

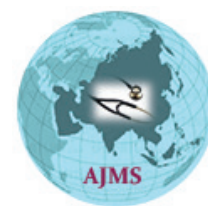

\section{A B S T R A C T}

While SARS-CoV-2 infection continues to circulate around the world, there are still many uncertainties on how to treat the patients with this potentially deadly virus, and more importantly, for how long! COVID-19 causes many different symptoms, among which coagulopathy seems to play an essential role in the survival prognosis of patients. While medical centers worldwide have developed various algorithms for preventing thrombosis in COVID-19 patients, there are still no clear guidelines on the length of thromboprophylaxis therapy, target groups who should receive suitable anticoagulant prophylaxis, and even the choice of the most appropriate agent for such treatment.

Key words: COVID-19; Coronavirus; Coagulopathy; Disseminated intravascular coagulation; Thrombosis; Deep vein thrombosis; Pulmonary embolism; Venous thromboembolism; Homeostasis; Acute ischemia

\section{Access this article online}

Website:

http://nepjol.info/index.php/AJMS DOI: 10.3126/ajms.v12i7.36838

E-ISSN: 2091-0576

P-ISSN: $2467-9100$

Copyright (c) 2021 Asian Journal of Medical Sciences

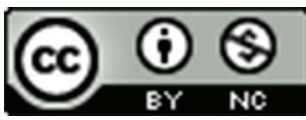

This work is licensed under a Creative Commons Attribution-NonCommercial 4.0 International License.

\section{INTRODUCTION}

The novel coronavirus (SARS-CoV-2), which first appeared in Wuhan, Hubei province of China, in December 2019, has turned into a dangerous widespread pandemic. It is a highly transmissible virus that is mainly transmitted by air. While many infected individuals have mild symptoms such as fever, fatigue, and cough, in severe cases, patients can deteriorate rapidly and develop a substantial pulmonary engagement, including pneumonia and acute Respiratory distress syndrome (ARDS). However, patients may present with many extrapulmonary complications of COVID-19 infection, such as septic shock, metabolic acidosis, and disseminated intravascular coagulation (DIC), and thromboembolic events. ${ }^{1}$

This article focuses on the prophylaxis of thrombosis in COVID-19 patients during the active phase of the disease and the early recovery period.

\section{MATERIALS AND METHODS}

A literature search was conducted through PubMed and Google Scholars using the Medical subject headings COVID; Coronavirus; Coagulopathy; Disseminated Intravascular 
Coagulation; Thrombosis; Deep Vein Thrombosis; Pulmonary Embolism; Venous Thromboembolism; Homeostasis and; and Acute Ischemia.

\section{HOW COVID-19 CAN PROMOTE COAGULATION AND THROMBOSIS}

Although the exact mechanisms through which coronavirus induces thromboembolic events are not clearly understood, there are currently many hypotheses that include the hypercoagulable state in COVID patients based on an intensified inflammatory response which in turn leads to thrombo-inflammation ${ }^{2}$. Other proposed mechanisms are cytokine storm, complement activation, and endothelial cell damage. These mechanisms can directly compromise microcirculation (Figure 1). ${ }^{2-4}$ Emerging evidence suggests the virus itself can probably activate the coagulation cascade through ACE2-mediated viral entry and tissue damage, ${ }^{5}$ as well as dysregulation of the renin-angiotensinaldosterone system (RAAS), ${ }^{6}$ which are thought to be unique to COVID-19. There is cumulating evidence that microcirculatory compromise is the hallmark of the COVID-19 hypercoagulable state. ${ }^{7}$

Critically ill patients fulfill the three criteria of Virchow's triad, namely; reduced venous flow from immobility, prothrombotic changes as a result of an acute inflammatory state as well as endothelial damage within microvessels due to direct action of SARS-CoV-2 (ACE receptor)increase the risk of thrombotic events.

Thrombotic events in COVID -19 patients can further be classified into venous, arterial, and microcirculatory events.

\section{Venous thromboembolism}

The most common thrombotic manifestation of COVID-19 is by far pulmonary embolism. Middeldorp et al., ${ }^{8}$ reported a higher incidence of thrombotic complications in their ICU patient population (7-day and 14-day) compared to the patients admitted on the wards, while all patients received a prophylactic dose of anticoagulant upon admission. ${ }^{8}$ Another study conducted in France by Helms et al., which included150 patients with COVID-19 associated acute respiratory distress syndrome (ARDS), showed a VTE rate of $18 \%$, with PE being most common. ${ }^{9}$ Even though current data is not enough to properly categorize patients into a high thrombosis risk group, it has been suggested that elderly, Caucasian, and African-American ethnicities may be more prone to develop a hypercoagulable state. ${ }^{10,11}$

\section{Arterial thrombosis}

There has been a surging number of reported arterial thrombosis cases and ischemic events in

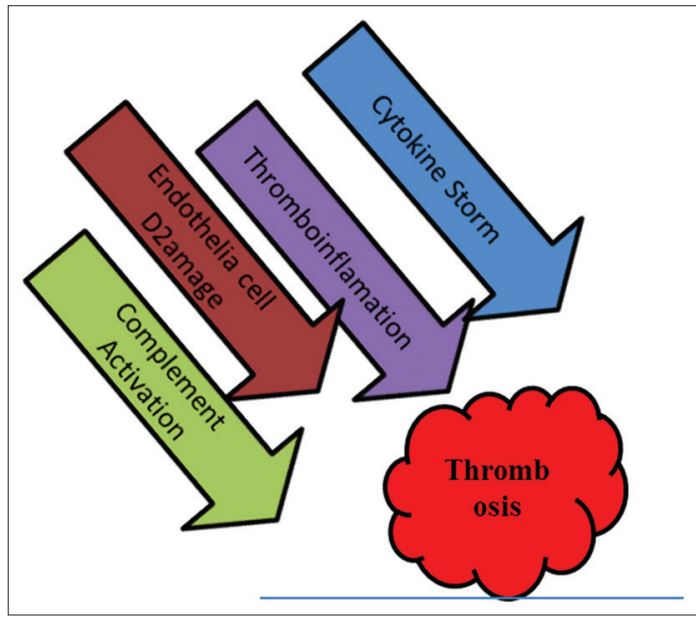

Figure 1: Proposed Mechanisms of Thromboembolism in COVID-19

COVID-19 patients. ${ }^{12,13}$ Acute mesenteric ischemia, in which preliminary pathological evidence showed bowel necrosis with small vessel thrombosis involving the submucosal arterioles, thereby pointing to an in-situ thrombosis ${ }^{14}$. In a study by Lodigiani et al., which included 388 patients with COVID-19, the incidence of acute coronary syndromes was $1.1 \%{ }^{15}$. Troponin levels have been noted to be significantly higher in the non-survivors, which may provide prognostic value. ${ }^{16} \mathrm{~A}$ retrospective study of admitted COVID-19 patients by Oxley et al. reported an alarming seven-fold increase in large vessel strokes in the $<50$-year-old age group. ${ }^{17}$ Another case series reports three patients with COVID-19 presenting with strokes and limb ischemia. ${ }^{18}$ Klok et al., also reported a $3.7 \%$ incidence of arterial thrombosis among COVID -19 patients. ${ }^{19}$

\section{Microvascular thrombosis}

Several clinical reports have demonstrated thrombotic microangiopathy (TMA) in patients with COVID-19, most notably including autopsies. ${ }^{20-22}$ In a postmortem study by Menter et al., five out of eleven patients showed microthrombi evidence in lung autopsies. ${ }^{21}$ Ackermann et al., presented a case series of widespread thrombosis along with severe endothelial injury and the presence of the virus inside the cells in the lung autopsies of seven COVID-19 patients. The researchers also reported that alveolar microthrombi were 9 times more prevalent in COVID-19 patients than in those with the severe form of influenza $(p<0.001) .{ }^{22}$ Furthermore, significantly elevated levels of VWF and FVIII in COVID-19 patients suggest endothelial activation in these patients., ${ }^{9,22}$ Endothelial damage, in turn, is a major promoting factor for thrombosis. The observation that male sex, obesity, hypertension, anddiabetes are poor prognostic factors for severe disease with COVID-19further supports this theory due to the presence of endothelial dysregulation at baseline in these patients. ${ }^{3}$ 


\section{MONITORING LABORATORY MARKER INDICATING THROMBOSIS RISK}

Based on new data, it appears increasingly essential to routinely monitor $\mathrm{D}$-dimer, fibrinogen, platelet count, and $\mathrm{PT} / \mathrm{aPT}$ T to assist in anticipating and managing thrombotic complications. ${ }^{23} \mathrm{It}$ is now proven that a d-dimer level cutoff of $1.5 \mu \mathrm{g} / \mathrm{mL}^{24}$ can predict venous thromboembolic events with a sensitivity rate of $85 \%$ and specificity and $88.5 \%$. It also has a negative predictive value of $94.7 \% .^{24}$

\section{CURRENT ANTICOAGULANT AGENTS IN USE AND THEIR INDICATION}

At the moment, there are several classes of anticoagulants available for preventing and treating thromboembolic events in COVID-19 patients. Figure-2 summarizes the characteristics of an ideal anticoagulant for COVID-19 thromboprophylaxis.

\section{Heparin}

Heparin has an established place in preventing and treating venous thrombosis. ${ }^{25}$ The sulfated nature of its constituent HS glycosaminoglycan chains confers heparin with the highest negative charge density of any known biomolecule. ${ }^{26}$ This charge allows heparin to strongly and selectively interact with an immense number of proteins, the most classic being its interaction with serine protease inhibitor antithrombin-III (AT3) that provides its anticoagulant activity. ${ }^{27}$

Heparin's anti-inflammatory effect has long been proven, which is achieved through different mechanisms. ${ }^{28}$

Heparin also has shown antiviral properties against enveloped viruses, including coronaviruses. Some recent data suggest that soluble heparin interacts with the SARSCoV-2 spike protein and inhibits SARS-CoV-2 spike pseudo-virus entry, ${ }^{29-31}$ which could potentially benefit patients suffering from COVID-19 infection.

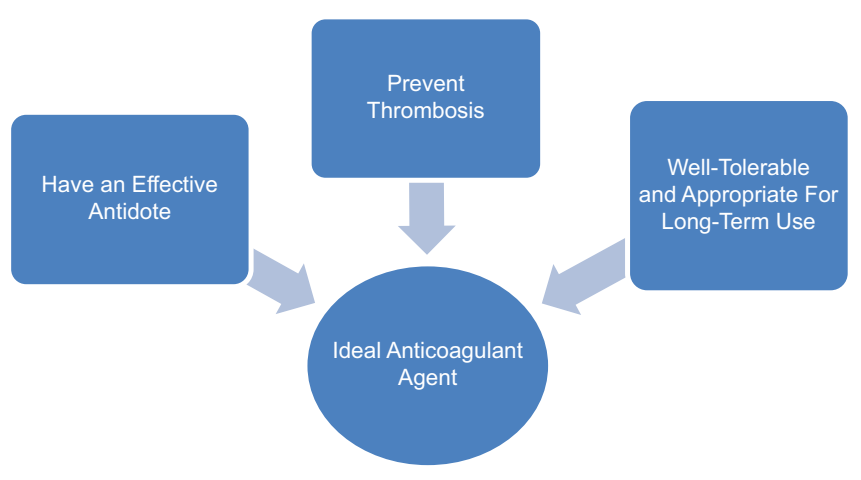

Figure 2: What is required from an ideal Anticoagulant Agent
Heparin action can be entirely reversed by protamine sulfate; nevertheless, it's short half-life and the need to constantly monitor aPPT makes it challenging to use heparin routinely as a prophylactic measure. On the other hand, Inhaled nebulized heparin ${ }^{32}$ is gaining more interest, and its efficacy in COVID Patients is being investigated in several clinical trials. ${ }^{33,34}$

\section{Low molecular weight heparin}

This class of anticoagulant drugs is routinely used both for prophylaxis and treatment of thromboembolic events in COVID-19 patients. Table-1 illustrates currently available along with their half-lives and molecular weights. LMWH has less effect on thrombin compared to heparin but about the same impact on Factor $\mathrm{Xa} .{ }^{35}$ Due to its renal clearance, LMWH is avoided in patients with kidney disease with a $\mathrm{CrCl} \leq 30,{ }^{36}$ in whom unfractionated heparin can be used safely. In the case of overdose, the anticoagulant effects of LMWH are only partially reversible with protamine sulfate. $^{37}$

\section{Fondaparinux}

Fondaparinux is an indirect factor X inhibitor. It has a halflife of 17-21 hours. ${ }^{38}$ Recent studies suggest that patients with mild to moderate COVID may avoid fondaparinux due to a relatively high bleeding risk. It is also contraindicated in patients with $\mathrm{crcl}<30 .{ }^{39}$

\section{Suledoxide}

Sulodexide, traded as Aterina, is a highly purified mixture of glycosaminoglycans composed of low molecular weight heparin $(80 \%)$ and dermatan sulfate $(20 \%)$. In addition to thrombosis prophylaxis, suledoxide is used off-label in some countries to treat reperfusion injury and diabetic retinopathy. Unlike other heparins, ${ }^{40,41}$ SDX can be administered orally with sufficient intestinal absorption providing a median bioavailability of approximately $40 \%$, eliminating the fear of needles of LMWH injections. ${ }^{42}$ Suledoxide is safe to use in renal insufficiency and is less likely related to HIT, major bleeding, and drug-induced hypersensitivity than LMWH. All these features render Suledoxide the potential to be a real alternative to low molecular weight heparins in preventing COVID-19 induced vascular complications. ${ }^{42}$

\section{Direct factor $\mathrm{X}$ inhibitor}

The DOACs include the direct thrombin inhibitor Dabigatran and Argatroban, and the factor Xa inhibitors. It is a zymogen which means, Factor $\mathrm{X}$ is activated either via the intrinsic pathway or the extrinsic pathway (Through factor IXa and factor VIIa/tissue factor, respectively). ${ }^{43}$

Currently, there are four clinically approved direct FXa inhibitors for use, which are Rivaroxaban (approved in 


\begin{tabular}{llcc}
\hline \multicolumn{2}{l}{ Table 1: List of currently available Law molecular weight heparins } \\
\hline LMWH & Brand name & $\begin{array}{c}\text { Half-life } \\
\text { (Subcutaneous) }\end{array}$ & Molecular weight \\
\hline Ardeparin & Normiflo & 3.3 hours & $5500-6500$ \\
Bemiparin & Ivor & $5-6$ hours & 3600 \\
Certoparin & SandoparinEmbolex & $3-4$ hours & 5400 \\
Dalteparin & Fragmin & $3.5-4$ hours & 6000 \\
Enoxaparin & Clexane, Lovenox & 4.5 hours & 4500 \\
Nadroparin & Fraxiparine & $3-4$ hours & 4300 \\
Parnaparin & Fluxum & $3-4$ hours & 5000 \\
Reviparin & Clivarin & 3 hours & 4400 \\
Tanziparin (Logiparin) & Innohep & 3.9 hours & 6500 \\
\hline
\end{tabular}

2011; Xarelto), Apixaban (2012; Eliquis), Edoxaban (2015; Savaysa), and Betrixaban (2017; Bevyxxa). ${ }^{43,44}$ The FXa inhibitors have demonstrated remarkable anti-inflammatory effects in human subjects. A Japanese study has recently reported the anti-inflammatory effects of Rivaroxaban and Apixaban in patients with atrial fibrillation. ${ }^{45}$ The antiinflammatory effect of Apixaban was also observed in the acute phase of ischemic stroke patients. ${ }^{46}$ A similar study has revealed that Rivaroxaban caused a significant reduction in the levels of D-dimer and IL-6 in patients with atrial fibrillation. ${ }^{47}$ These results indicate that blocking the activity of FXa may be beneficial to prevent the SARS-CoV-2associated coagulopathies and dampen the virus-triggered excessive immune response.

These Direct Oral Anticoagulants all have a rapid onset of action, and each has a predictable therapeutic response requiring no monitoring ${ }^{48}$ unlike the older anticoagulants, such as warfarin. There are currently two reversal agents available for DOACS, namely Andexanet alfa for the reversal of Rivaroxaban and Apixaban and Idarucizumab for the reversal of Dabigatran. Moreover, Ciraparantag, a potential "universal" reversal agent, is currently under clinical development. ${ }^{48}$

\section{Vitamin $\mathrm{K}$ inhibitors}

Hospitalized patients with COVID on Vitamin K inhibitors, such as warfarin, are placed on parenteral heparin instead since there is an increased instability of prothrombin time (PT)/INR due to the high variability of vitamin $\mathrm{K}$ metabolism, diet, fasting, co-medications, liver impairment, and heart failure in patients hospitalized with COVID-19 treated with VKA.43,49

\section{ADJUVANT THERAPY}

\section{TPA}

Tissue plasminogen activator (tPA) in COVID-19 ARDS Evidence of microthrombi and coagulopathy in critically ill COVID- 19 patients prompted the possibility of tissue plasminogen activator (tPA) as a potential treatment. ${ }^{45}$

\section{Inflammatory cytokines inhibition}

Tocilizumab, ${ }^{46}$ an interleukin-6 inhibitor, and Anakinra- IL1 inhibitor, ${ }^{47}$ have been used in the setting of cytokine release syndrome in COVID-19, and recent pilot prospective data suggest a survival benefit if used early in the course of the disease. ${ }^{48}$

\section{PROPHYLACTIC ANTICOAGULANT THERAPY IN HOSPITALIZED COVID-19 PATIENTS}

A coagulation disorder (hypercoagulability) induced by systemic inflammatory state, endothelial activation, hypoxia, and immobilization may lead to a hypercoagulable state. The International Society now recommends the use of prophylactic doses of LMWH on Thrombosis and Haemostasis (ISTH) for all hospitalized COVID-19 patients, unless they have active bleeding or platelet count $<25$ $\times 109 /$ L. $^{50}$ In hospitalized, critically ill patients, at the moment, low molecular weight heparin or unfractionated heparin is preferred over oral anticoagulants because of their shorter half-lives, ability to be administered intravenously, or subcutaneously, and fewer drug-drug interactions. ${ }^{51,52}$ Table- 2 contains examples of prophylactic anticoagulant therapy protocols, recommended by health authorities worldwide.

\section{NEED FOR ANTICOAGULANT PROPHYLAXIS POST-DISCHARGE, WHEN AND FOR HOW LONG:}

Even though COVID-19 has been associated with an increased risk of thrombosis and predominantly venous thromboembolism, Post-recovery anticoagulant protocols remain controversial among experts.

In a retrospective study by Patel Rushad et al., of 163 covid patients, the cumulative incidence of overall (venous and arterial) thrombosis was $2.5 \%$ at day 30 after discharge. ${ }^{53}$

In King's college hospital, a retrospective study of 18159 hospital-discharged COVID-19 patients in 2019 revealed that 85 experienced post-discharge HA-VTE, at 


Table 2: Examples of Currently Available
Prophylactic Anticoagulant Therapy Protocols in
Hospitalized COVID -19 Patients

a median of 29 days (interquartile range, 16-51 days) postdischarge. Fifty-six episodes (66\%) of HA-VTE occurred within 42 days of discharge, giving a rate of 3.1 per 1000 discharges. ${ }^{54}$

Increasing data suggest that COVID-19 RNA can still be detected in the respiratory specimen collected from recovered patients up to 12 weeks after recovery; however, the replication-competent virus has not been isolated beyond 3 weeks after symptom onset. ${ }^{55}$ This data further support the need for a thrombosis prophylaxis regimen in the early weeks after recovering from COVID-19.

According to the National Institute of Health's current protocol, patients could be considered for COVID-19 VTE prophylaxis only if the post-discharge criteria are met. ${ }^{56}$ The American Society for Hematology expert panel recommends that any decision to use extended post-discharge thromboprophylaxis with anticoagulation or aspirin should consider the individual patient's VTE risk factors, such as reduced mobility, coagulopathy, and bleeding risk. ${ }^{57}$ The International Medical Prevention Registry on Venous Thromboembolism (IMPROVE) VTE risk score has been used as a measure to identify patients who would benefit from extended-use prophylaxis with LMWH. ${ }^{58}$ Current Protocols suggest that patients hospitalized with COVID-19, who present with an improved VTE score of $>3$, an elevated D-dimer level ( $>2 \times$ upper limit of normal), and 2 or more of the following characteristics: age $>60$, previous VTE, known thrombophilia, current cancer, should be strongly considered for extended thromboprophylaxis up to 39-
45 days post-discharge either with prophylactic dose LMWH or Rivaroxaban. ${ }^{59,60}$ For patients who have been empirically started on therapeutic anticoagulation for suspected PE, the ASH panel recommends that they remain anticoagulated for at least 3 months. Furthermore, confirmed VTE cases should be considered "provoked" and treated for 3-6 months duration. ${ }^{2}$

\section{THROMBOTIC EVENTS DESPITE THROMBOPROPHYLAXIS IN COVID-19 PATIENTS}

There are numerous examples of patient's thrombotic events despite current treatment. In a large study in the Netherlands, 184 ICU patients with COVID-19 who were all on at least standard thromboprophylaxis had a $27 \%$ cumulative incidence of VTE, with pulmonary embolism (PE) being most frequent $(81 \%) .{ }^{24} \mathrm{~A}$ Spanish retrospective cohort study of 1127 COVID-19 patients also reported a $6.1 \%$ incidence of thromboembolic events despite standard thromboprophylaxis. ${ }^{61}$

A prospective cohort study by Jimenez-Guiu et al., of 67 non-critically ill patients admitted to the hospital for COVID-19 pneumonia showed a high risk of DVT despite receipt of correct, standard thromboprophylaxis. ${ }^{61}$

\section{CONCLUSION}

To conclude, current criteria for prophylactic anticoagulation in COVID-19 patients seems to be inadequate as there are increasing reported cases of thromboembolic events despite prophylactic anticoagulant therapy among hospitalized patients. Moreover, there is currently no agreement on the choice and dosage of anticoagulant agents among experts, while there is a high risk of bleeding among patients due to the COVID-19 induced coagulopathy. In the case of post-discharge prophylaxis in COVID-19 patients, evidence suggests that all COVID patients need to be on anticoagulant therapy for 45 to 90 days, even though thrombotic risk commonly persists despite initiation of anticoagulation. It is also wise to seek new drugs and delivery modes such as inhalation, which would be more efficient in preventing Hypercoagulability and reducing treatment's side effects.

\section{REFERENCES}

1. Gupta A, Mahesh V. Madhavan, Kartik S, Nandini N, Shiwani M, et al. Extrapulmonary manifestations of COVID-19. Nat Med. 2020; 26: 1017-1032.

https://doi.org/10.1038/s41591-020-0968-3

2. Abou-Ismail MY, Diamond A, Kapoor, S, Arafah $Y$ and 
Nayak L. The hypercoagulable state in COVID-19: Incidence, pathophysiology, and management. Thromb Res. 2020; 194:101-115.

https://doi.org/10.1016/j.thromres.2020.06.029

3. Varga Z, Flammer A, Steiger P, Haberecker M, Andermat R, Zinkernagel $A$, et al. Endothelial cell infection and endotheliitis in COVID-19. Lancet 2020; 395:1417-1418.

https://doi.org/10.1016/S0140-6736(20)30937-5

4. Goshua G, Pine A, Meizlish M, Chang C, Zhang H, Bahel P, et al. Endotheliopathy in COVID-19-associated coagulopathy: evidence from a single-centre, cross-sectional study. Lancet Haematol.2020;7: e575-e582.

https://doi.org/10.1016/S2352-3026(20)30216-7

5. Lei C, Qian K, Li T, Zhang S, Fu W, Ding M, et al. Neutralization of SARS-CoV-2 spike pseudotyped virus by recombinant ACE2Ig. Nat Commun. 2020; 11: 1-5.

https://doi.org/10.1038/s41467-020-16048-4

6. Wentao N, Xiuwen Y, Yang D, Bao J, Li R, Xiao Y, et al. Role of angiotensin-converting enzyme 2 (ACE2) in COVID-19. Crit Care. 2020; 24: 422.

https://doi.org/10.1186/s13054-020-03120-0

7. Roberts KA, Colley L, Agbaedeng TA, EllisonHughes GM and Ross MD. Vascular Manifestations of COVID-19 - Thromboembolism and Microvascular Dysfunction. Front Cardiovasc Med. 2020;7.

https://doi.org/10.3389/fcvm.2020.598400

8. Middeldorp S, Coppens M, van Haaps T, Foppen M, Vlaar A, Müller $\mathrm{M}$, et al. Incidence of venous thromboembolism in hospitalized patients with COVID-19. J. Thromb Haemost.2020; 18: 1995-2002.

https://doi.org/10.1111/jth.14842

9. Helms J, Tacquard C, Severac F, Leonard-Lorant I, Ohana M, Delabranche $X$, et al. High risk of thrombosis in patients with severe SARS-CoV-2 infection: a multicenter prospective cohort study. Intensive Care Med. 2020;1-10.

https://doi.org/10.1007/s00134-020-06062-x

10. Cui $S$, Chen S, Li X, Liu S and Wang F. Prevalence of venous thromboembolism in patients with severe novel coronavirus pneumonia. J Thromb Haemost. 2020;

https://doi.org/10.1111/jth.14830

11. Fogarty H, Townsend L, Ni Cheallaigh C, Bergin C, MartinLoeches I, Browne P, et al. COVID19 coagulopathy in Caucasian patients. Br J Haematol. 2020.

https://doi.org/10.1111/bjh.16749

12. Etkin Y, Conway AM, Silpe J, Qato K, Carroccio A, ManvarSingh P, et al. Acute Arterial Thromboembolism in Patients with COVID-19 in the New York City Area. Ann Vasc Surg. 2021; 70: $290-294$.

https://doi.org/10.1016/j.avsg.2020.08.085

13. Singh B, Aly R, Kaur P, Gupta S, Vasudev R, Virk HS, et al. COVID-19 Infection and Arterial Thrombosis: Report of Three Cases. Ann Vasc Surg. 2021; 70: 314-317. https://doi.org/10.1016/j.avsg.2020.08.115

14. Parry $\mathrm{AH}$, Wani $\mathrm{AH}$ and Yaseen $\mathrm{M}$. Acute Mesenteric Ischemia in Severe Coronavirus-19 (COVID-19): Possible Mechanisms and Diagnostic Pathway. Acad Radiol. 2020;27: 1190. https://doi.org/10.1016/j.acra.2020.05.016

15. Lodigiani C, lapichinoc G, Carenzoc L, Cecconib M, Ferrazzia P, Sebastian $\mathrm{T}$, et al. Venous and arterial thromboembolic complications in COVID-19 patients admitted to an academic hospital in Milan, Italy. Thromb Res. 2020; 191: 9-14. https://doi.org/10.1016/j.thromres.2020.04.024
16. Aboughdir M, Kirwin T, Abdul Khader A and Wang B. Prognostic Value of Cardiovascular Biomarkers in COVID-19: A Review. Viruses. 2020;12(5):527. https://doi.org/10.3390/v12050527.

17. Oxley TJ, Mocco J, Majidi S, Kellner C, Shoirah H, Singh IP, et al. Large-Vessel Stroke as a Presenting Feature of Covid-19 in the Young. N Engl J Med. 2020; 382: e60. https://doi.org/10.1056/NEJMc2009787

18. Zhai P, Ding Y and Li Y. Impact of COVID-19 on ischemic stroke: A case report. https://doi.org/10.21203/rs.3.rs-20393/v1

19. Klok FA, Kruip MJHA, van der Meer NJM, Arbous MS, Gommers D, Kant KM, et al. Confirmation of the high cumulative incidence of thrombotic complications in critically ill ICU patients with COVID-19: An updated analysis. Thromb Res. 2020; 191:148-150. https://doi.org/10.1016/j.thromres.2020.04.041

20. Wichmann D, Sperhake JP, Lütgehetmann M, Steurer S, Edler C, Heinemann A, et al. Autopsy Findings and Venous Thromboembolism in Patients With COVID-19. Ann Intern Med. 2020.

https://doi.org/10.7326/M20-2003

21. Menter T, Haslbauer J, Nienhold R, Savic S, Hopfer H, Deigendesch N, et al. Postmortem examination of COVID-19 patients reveals diffuse alveolar damage with severe capillary congestion and variegated findings in lungs and other organs suggesting vascular dysfunction. Histopathology. 2020; 77: 198-209.

https://doi.org/10.1111/his.14134

22. Ackermann M, Verleden SE, Kuehnel M, Haverich $A$, Welte T, Laenger F, et al. Pulmonary Vascular Endothelialitis, Thrombosis, and Angiogenesis in Covid-19. N Engl J Med. 2020; 383(2): 120-128.

https://doi.org/10.1056/NEJMoa2015432

23. Hadid T, Kafri $Z$ and Al-Katib A. Coagulation and anticoagulation in COVID-19. Blood Rev. 2021. 47. https://doi.org/10.1016/j.blre.2020.100761

24. Garcia-Olivé I, Sintes H, Radua J, Abad Capa J and Rosell A. D-dimer in patients infected with COVID-19 and suspected pulmonary embolism. Respir Med. 2020; 169: 106023. https://doi.org/10.1016/j.rmed.2020.106023

25. Gray E, Mulloy B and Barrowcliffe TW. Heparin and low-molecularweight heparin. Thromb Haemost. 2008;99(5):807-818. https://doi.org/10.1160/TH08-01-0032.

26. Weiss RJ, Esko JD and Tor Y. Targeting Heparin- and Heparan Sulfate-Protein Interactions. Org Biomol Chem. 2017; 15: 56565668. https://doi.org/10.1039/C7OB01058C

27. Hippensteel JA, LaRiviere WB, Colbert JF, Langouët-Astrié CJ and Schmidt EP. Heparin as a therapy for COVID-19: current evidence and future possibilities. Am J Physiol. - Lung Cell. Mol Physiol. 2020; 319: L211-L217. https://doi.org/10.1152/ajplung.00199.2020

28. Young E. The anti-inflammatory effects of heparin and related compounds. Thrombosis Research.2008;122(6):743-752. https://doi.org/10.1016/j.thromres.2006.10.026

29. Lang J, Yang N, Deng J, Liu K, Yang P, Zhang G, et al. Inhibition of SARS pseudovirus cell entry by lactoferrin binding to heparan sulfate proteoglycans. PloS one. 2011. https://doi.org/10.1371/journal.pone.0023710

30. Mycroft-West C, Su D, Elli S, Li Y, Guimond S, Miller G, et al. 
The 2019 coronavirus (SARS-CoV-2) surface protein (Spike) S1 Receptor Binding Domain undergoes conformational change upon heparin binding. bioRxiv. 2020;

https://doi.org/10.1101/2020.02.29.971093

31. Vicenzi E, Canducci F, Pinna D, Mancini N, Carletti S, Lazzarin A et al. Coronaviridae and SARS-associated coronavirus strain HSR1. Emerg Infect Dis. 2004;10(3):413-418. https://doi.org/10.3201/eid1003.030683

32. Conzelmann C, Müller J, Perkhofer L, Sparrer K, Zelikin A Münch $\mathrm{J}$ and Kleger $\mathrm{A}$. Inhaled and systemic heparin as a repurposed direct antiviral drug for prevention and treatment of COVID-19. Clin Med. 2020; 20: e218-e221. https://doi.org/10.7861/clinmed.2020-0351

33. Nebulized Heparin for the Treatment of COVID-19 Induced Lung Injury - Full Text View - ClinicalTrials.gov. https://clinicaltrials.gov/ct2/show/NCT04397510.

34. Nebulized Heparin in Severe Acute Respiratory Syndrome COVID-19 - Full Text View - ClinicalTrials.gov. https://clinicaltrials.gov/ct2/show/NCT04530578.

35. Buyue Y, Misenheimer TM and Sheehan JP. Low molecular weight heparin inhibits plasma thrombin generation via direct targeting of factor IXa: contribution of the serpin-independent mechanism. J Thromb Haemost. 2012;10(10):2086-2098. https://doi.org/10.1111/j.1538-7836.2012.04892.x

36. LMW heparin dosing renal insufficiency (adults) - UpToDate. https://www.uptodate.com/contents/image?imageKey=HEME \%2F90258and topicKey= HEME\%2 F127926\&source=see_link.

37. Crowther MA, Berry LR, Monagle PT and Chan AKC. Mechanisms responsible for the failure of protamine to inactivate low-molecular-weight heparin. British journal of haematology. 2002.

https://doi.org/10.1046/j.1365-2141.2002.03233.x

38. Gracia DA, Baglin TP, Weitz JI. And Samana MM. Parenteral anticoagulants: Antithrombotic Therapy and Prevention of Thrombosis, $9^{\text {th }}$ ed: American College of Chest Physicians Evidence-Based Clinical Practice Guidelines. Chest. 2021; 1419(2): E24S-E43S.

https://doi.org/10.1378/chest.11-2291

39. Al-Shaer MH and Ibrahim T. Safety and Efficacy of Fondaparinux in Renal Impairment. J Pharm Technol JPT Off Publ Assoc Pharm Tech. 2015;31(4):161-166. http://dx.doi.org/10.1177\%2F8755122514567316

40. Coccheri S and Mannello F. Development and use of sulodexide in vascular diseases: implications for treatment. Drug Des Devel Ther. 2013;8: 49-65. https://doi.org/10.2147/DDDT.S6762

41. Adam LauverD, Booth EA, WhiteAJ, Poradosu Eand LucchesiBR. Sulodexide attenuates myocardial ischemia/reperfusion injury and the deposition of C-reactive protein in areas of infarction without affecting hemostasis. The Journal of pharmacology and experimental therapeutics.2005; 312 (2): 794-800. https://doi.org/10.1124/jpet.104.075283

42. Szolnoky G. Sulodexide may be a real alternative to low molecular weight heparins in the prevention of COVID-19 induced vascular complications. Dermatol Ther. 2020;33(6): e14437. https://doi.org/10.1111/dth.14437

43. Testa S, Paoletti O, Giorgi-Pierfranceschi M and Pan A. Switch from oral anticoagulants to parenteral heparin in SARS-CoV-2 hospitalized patients. Intern Emerg Med. 2020; 15: 751-753. https://doi.org/10.1007/s11739-020-02331-1
44. Turshudzhyan A. Anticoagulation Options for Coronavirus Disease 2019 (COVID-19)-Induced Coagulopathy. Cureus. 2020;12(5): e8150. https://doi.org/10.7759/cureus.8150

45. Wang J, Hajizadeh N, Moore EE, Mclntyre RC, Moore PK, Veress LA, et al. Tissue plasminogen activator (tPA) treatment for COVID-19 associated acute respiratory distress syndrome (ARDS): A case series. J Thromb Haemost. 2020;18(7):17521755. https://doi.org/10.1111/jth.14828

46. Liu D, Zhang T, Wang Y and Xia L. Tocilizumab: The Key to Stop Coronavirus Disease 2019 (COVID-19)-Induced Cytokine Release Syndrome (CRS)? Front. Med. 2020;7. https://doi.org/10.3389/fmed.2020.571597

47. Interleukin-1 Inhibitors. COVID-19 Treatment Guidelines https://www.covid19treatmentguidelines.nih.gov/immunebased-therapy/immunomodulators/interleukin-1-inhibitors

48. Sciascia $S$, Aprà F, Baffa A, Baldovino $S$, Boaro D, Boero R, et al. Pilot prospective open, single-arm multicentre study on off-label use of tocilizumab in patients with severe COVID-19. Clinical and experimental rheumatology. 2020; 38(3):529-532. https://pubmed.ncbi.nlm.nih.gov/32359035/(2020).

49. Turshudzhyan A. Anticoagulation Options for Coronavirus Disease 2019 (COVID-19)-Induced Coagulopathy. Cureus. 2020;12(5):e8150. https://doi.org/10.7759/cureus.8150

50. Thachil J, Tang N, Gando S, Falanga A, Cattaneo M, Levi M, et al. ISTH interim guidance on recognition and management of coagulopathy in COVID-19. Journal of thrombosis and haemostatis. 2020. https://doi.org/10.1111/jth.14810

51. Gozzo L, Viale P, Longo L, Vitale DC and Drago F. The Potential Role of Heparin in Patients With COVID-19: Beyond the Anticoagulant Effect. A Review. Front. Pharmacol. 2020; 11. https://doi.org/10.3389/fphar.2020.01307

52. Susen S, Ambroise Tacquard C, Godon A, Mansour A, Garrigue D, Nguyen P, et al. Prevention of thrombotic risk in hospitalized patients with COVID-19 and hemostasis monitoring. Crit Care. 2020; 24: 364. https://doi.org/10.1186/s13054-020-03000-7

53. Patell R, Bogue T, Koshy A, Bindal P, Merrill M, Aird W, et al. Post discharge thrombosis and hemorrhage in patients with COVID-19. Blood. 2020; 136(11): 1342-1346. https://doi.org/10.1182/blood.2020007938

54. Lit Covid. https://www.ncbi.nlm.nih.gov/research/coronavirus

55. CDC. Healthcare Workers. Centers for Disease Control and Prevention.

https://www.cdc.gov/coronavirus/2019-ncov/hcp/durationisolation.html

56. Antithrombotic Therapy. COVID-19 Treatment Guidelines. https://www.covid19treatmentguidelines.nih.gov/adjunctivetherapy/antithrombotic-therapy

57. COVID-19 and VTE-Anticoagulation - Hematology.org. https://www.hematology.org:443/covid-19/covid-19-and-vteanticoagulation.

58. Spyropoulos AC, Lipardi C, Xu J, Peluso C, Spiro T, De Sanctis Y, et al. Modified IMPROVE VTE Risk Score and Elevated D-Dimer Identify a High Venous Thromboembolism Risk in Acutely III Medical Population for Extended Thromboprophylaxis. TH Open. 2020; 04(01): e59-e65. 
https://doi.org/10.1055/s-0040-1705137

59. Cohoon KP, Mahé G, Tafur AJ and Spyropoulos AC. Emergence of institutional antithrombotic protocols for coronavirus 2019. Res Pract Thromb Haemost. 2020; 4: 510-517. https://doi.org/10.1002/rth2.12358

60. Li A, Garcia DA, Lyman GH and Carrier M. Direct Oral Anticoagulant (DOAC) versus Low-Molecular-Weight Heparin (LMWH) for Treatment of Cancer Associated Thrombosis (CAT): A Systematic Review and Meta-Analysis. Thromb Res.
2019;173: 158-163.

https://doi.org/10.1016/j.thromres.2018.02.144

61. Jimenez-Guiu $X$, Huici-Sánchez $M$, Romera-Villegas $A$, Izquierdo-Miranda A, Sancho-Cerro A, Vila-Coll R, et al. Deep vein thrombosis in non-critically ill patients with coronavirus disease 2019 pneumonia: deep vein thrombosis in non-intensive care unit patients. J Vasc Surg Venous Lymphat Disord. 2020; 9(3): 592-596.

https://doi.org/10.1016/j.jvsv.2020.08.028

\section{Author's contribution:}

SPHM-Concept and design of the study; prepared first draft of manuscript; VS- Review of manuscript; YD, ID-Reviewed the literature and manuscript preparation.

\section{Work Attributed to}

Department of Surgery and Organ Transplantation, Shalimov National Institute of Surgery and Transplantology.

Orcid ID:

Dr Seyed Pouriya Hosseini Mehr- (1) https://orcid.org/0000-0001-5226-2334

Prof Valentin Smorzhevskyi-@ https://orcid.org/0000-0001-8410-3944

Dr Yuliia Dzekunova- (iD https://orcid.org/0000-0002-8400-6789

Dr Igor Dmytrenko- id https://orcid.org/0000-0001-5849-3977

Source of funding: None, Conflicts of Interest: None. 